\title{
La economía mexicana al primer trimestre de 2014 y pronósticos de cierre del año
}

The Mexican Economy in the first quarter of $20 / 4$ and year-end forecasts

\author{
Oscar Antonio Miguel* " \\ Daiana Izbizaday Silva Gonda** :
}

\section{Resumen}

Se espera que la actividad global continúe recuperándose en 2014, impulsada principalmente por la recuperación económica en países avanzados. Por otro lado, se espera un menor crecimiento en las economías emergentes limitado por la falta de reformas estructurales y desequilibrios macroeconómicos en algunas economías, aunque impulsadas por una mayor demanda externa proveniente de economías avanzadas. Para el caso de la economía mexicana se espera un escenario macroeconómico optimista, debido a los resultados que arrojen las reformas estructurales aprobadas en 2013.

Palabras clave:

- Objetivos de política económica

- Política monetaria

- Análisis macroeconómico de desarrollo

\section{Abstract}

It is expected that the overall activity continues to recover in 2014, mainly driven by the economic recovery in advanced countries. On the other hand, slower growth in emerging economies is expected limited by the lack of structural reforms and macroeconomic imbalances in some economies, although driven by increased external demand from advanced economies. In the case of the Mexican economy an optimistic macroeconomic scenario is expected, due to the results that yield structural reforms adopted in 2013.

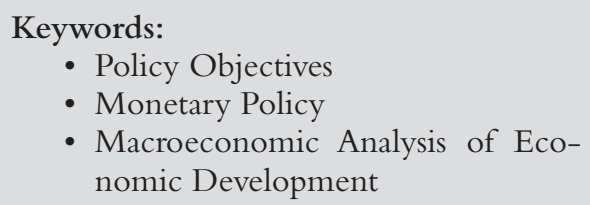

JEL: E61, E52, O11

De acuerdo con especialistas nacionales e internacionales, se espera que la actividad Económica Mundial continúe recuperándose en 2014, esto es, impulsada principalmente por la recuperación económica en países avanzados. Por otro lado, se espera un menor crecimiento en las economías emergentes limitado por la falta de reformas estructurales y desequilibrios macroeconómicos en algunas economías.

Como resultado de lo anterior y de acuerdo con el Fondo Monetario Internacional (FMI) se espera que la economía mundial crezca a una tasa de $3.6 \%$ en 2014 y para 2015 a una tasa de $3.9 \%$, por su parte para las economías avanzadas se proyecta crezcan 2.2 y $2.3 \%$, respectivamente, tanto para 2014 y 2015, mientras que para las economías emergentes se proyecta crezcan $4.9 \%$ para 2014 y $5.3 \%$ para el siguiente año.

* Profesor de la Facultad de Economía de la UNAM. - " * ** Ayudante de Profesor en la Facultad de Economía de la UNAM. 


\section{Gráfica I}

Proyecciones de la Economía Mundial, 2014 y 2015

(Variación porcentual)

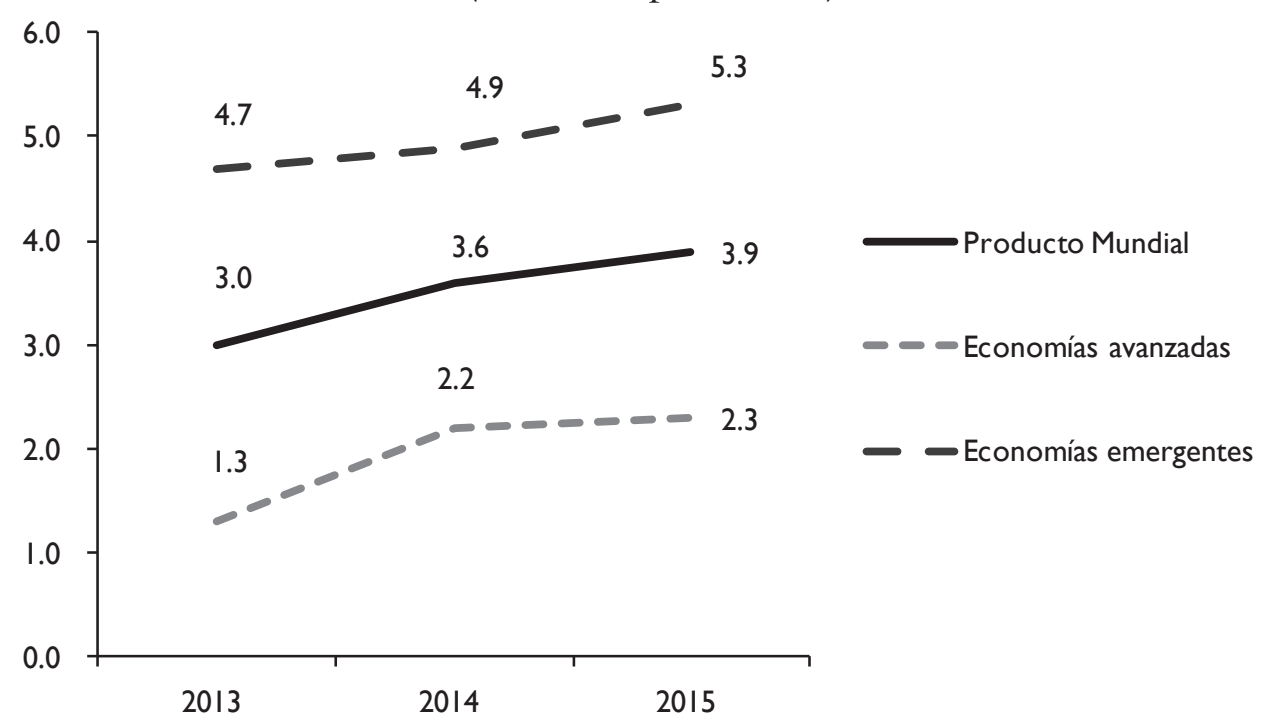

Fuente: elaboración propia con datos del FMI. Abril de 2014.

Asimismo y de acuerdo con los Precriterios Generales de Política Económica, que publicó recientemente la Secretaria de Hacienda y Crédito Público, se proyecta un escenario optimista para la economía mexicana.

\section{Producto Interno Bruto}

De acuerdo con los especialistas del Sector Privado encuestados por el Banco de México en marzo del presente año, pronostican que el valor real del Producto Interno Bruto (PIB) crezca a una tasa anual de $3.09 \%$, asimismo, de acuerdo con los pronósticos de la SHCP se espera que la economía mexicana crezca $3.9 \%$ al cierre de 2014, mientras que para 2015, se proyecta que el PIB registre un crecimiento anual de alrededor de 4.7 por ciento.

Cabe mencionar que la estimación del PIB para 2014 considera que la demanda interna en nuestro país se seguirá fortaleciendo y que comenzarán a observarse efectos de las reformas estructurales aprobadas en 2013 en materia financiera, de telecomunicaciones, energética, social y fiscal. 


\section{Gráfica 2}

\section{Expectativas de Crecimientos para 2014 del Sector Privado}

(Variación porcentual anual)

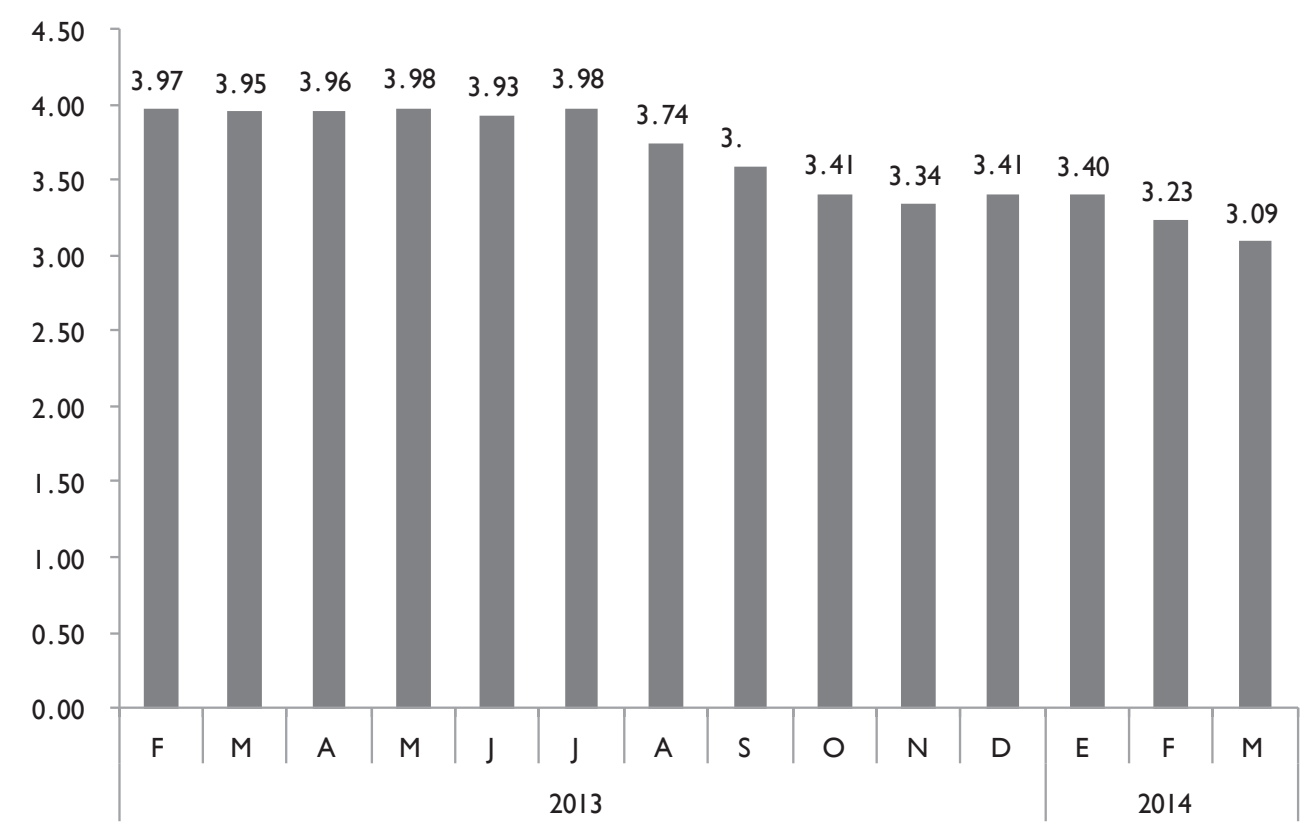

Fuente: elaboración propia con datos de la Encuesta Sobre las Expectativas de los Especialistas en Economía del Sector Privado. Banxico, marzo de 2014.

\section{Inflación}

Al cierre del primer trimestre de 2014 se registró una inflación anual de $3.76 \%$ (conforme a la variación del Índice Nacional de Precios al Consumidor), esto es, cifra inferior a lo observado al cierre del 2013, que fue de $3.97 \%$. Por otro lado, las expectativas de inflación para el cierre de 2014 y para el mediano plazo se mantienen dentro del objetivo del Banco de México. 


\section{Gráfica 3 \\ Inflación General}

(Variación mensual, anualizada)

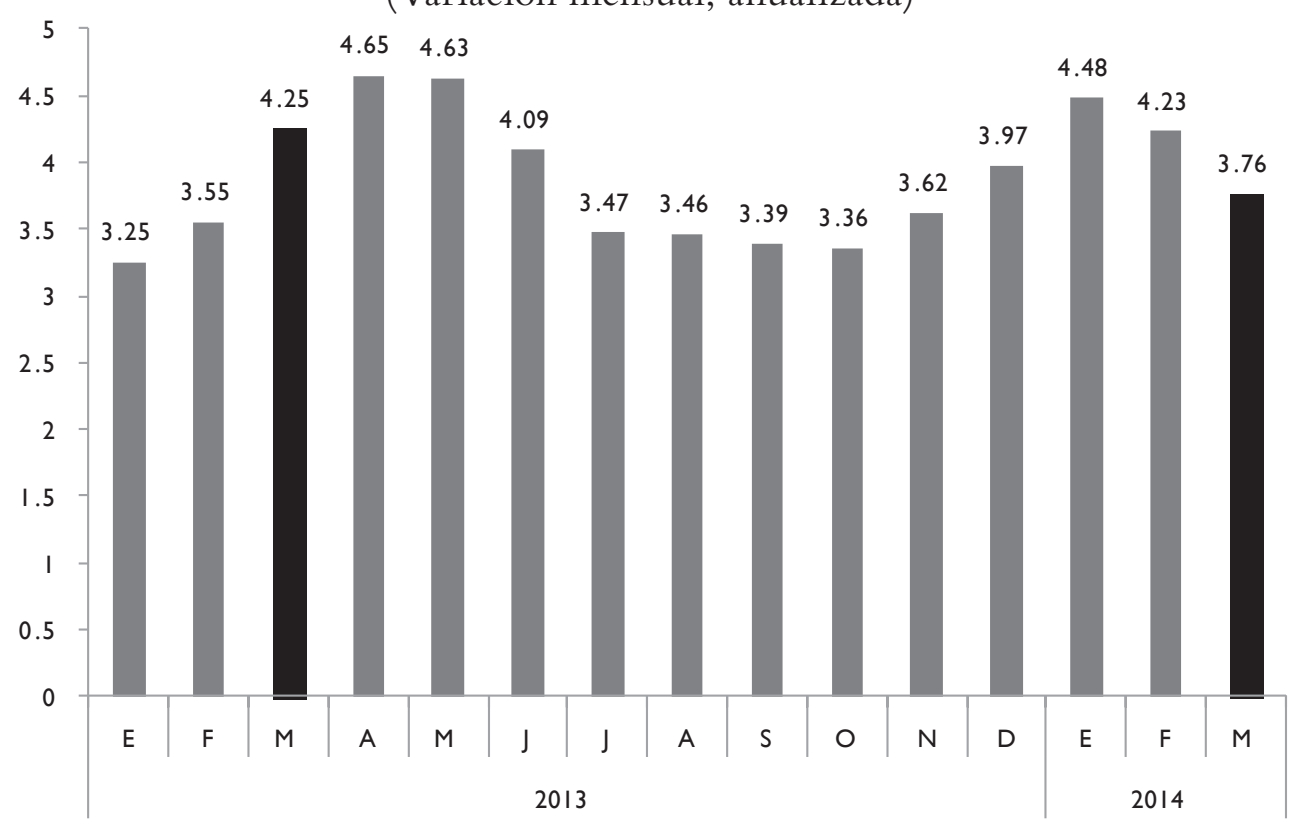

Fuente: elaboración propia con datos del INEGI.

\section{Empleo}

De acuerdo con las cifras emitidas por el Instituto Mexicano del Seguro Social (IMSS), el número de trabajadores asegurados totales al mes de marzo de 2014 ascendió a 16 millones 781 mil 325 personas, lo que representó un aumento de $3.1 \%$, respecto al mismo mes de 2013, e implicó un avance de 256 mil 264 plazas frente a lo registrado en diciembre de 2013. 


\section{Gráfica 4}

Trabajadores Registrados en el IMSS, 2013-2014

(Miles de trabajadores)

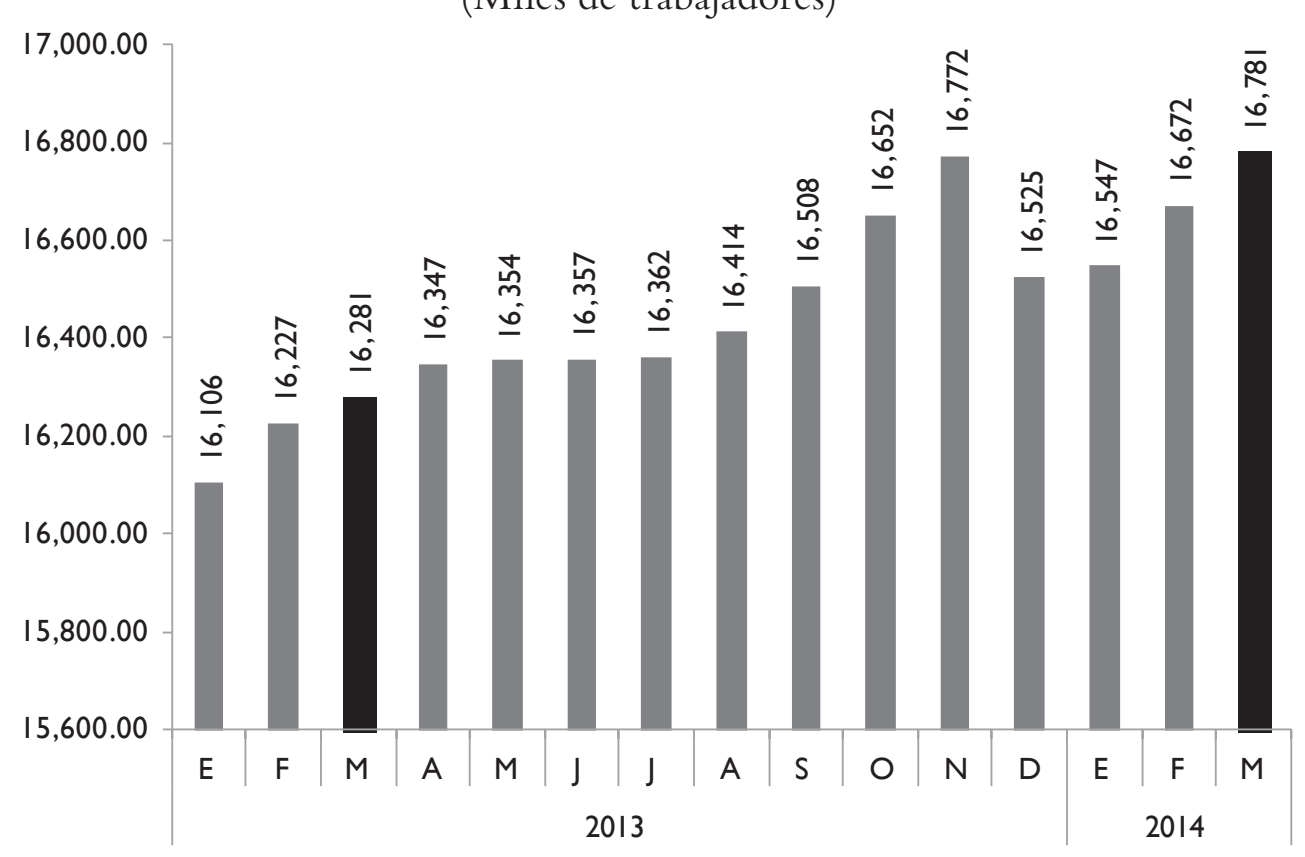

Fuente: elaboración propia con datos del IMSs.

Por su parte, la tasa de desocupación a nivel nacional que pública la Encuesta Nacional de Ocupación y Empleo (ENOE), que elabora el Instituto Nacional de Estadística y Geografía (INEGI), fue de 4.80 \% de la Población Económicamente Activa (PEA) al mes de marzo de 2014, esto es, cifra inferior a la reportada en el mismo mes de 2013, en donde la tasa de desocupación en el país se ubicó en 4.51 por ciento. 


\section{Gráfica 5}

Tasa de Desocupación mensual a nivel Nacional, 2013-2014

(Porcentaje respecto de la PEA)

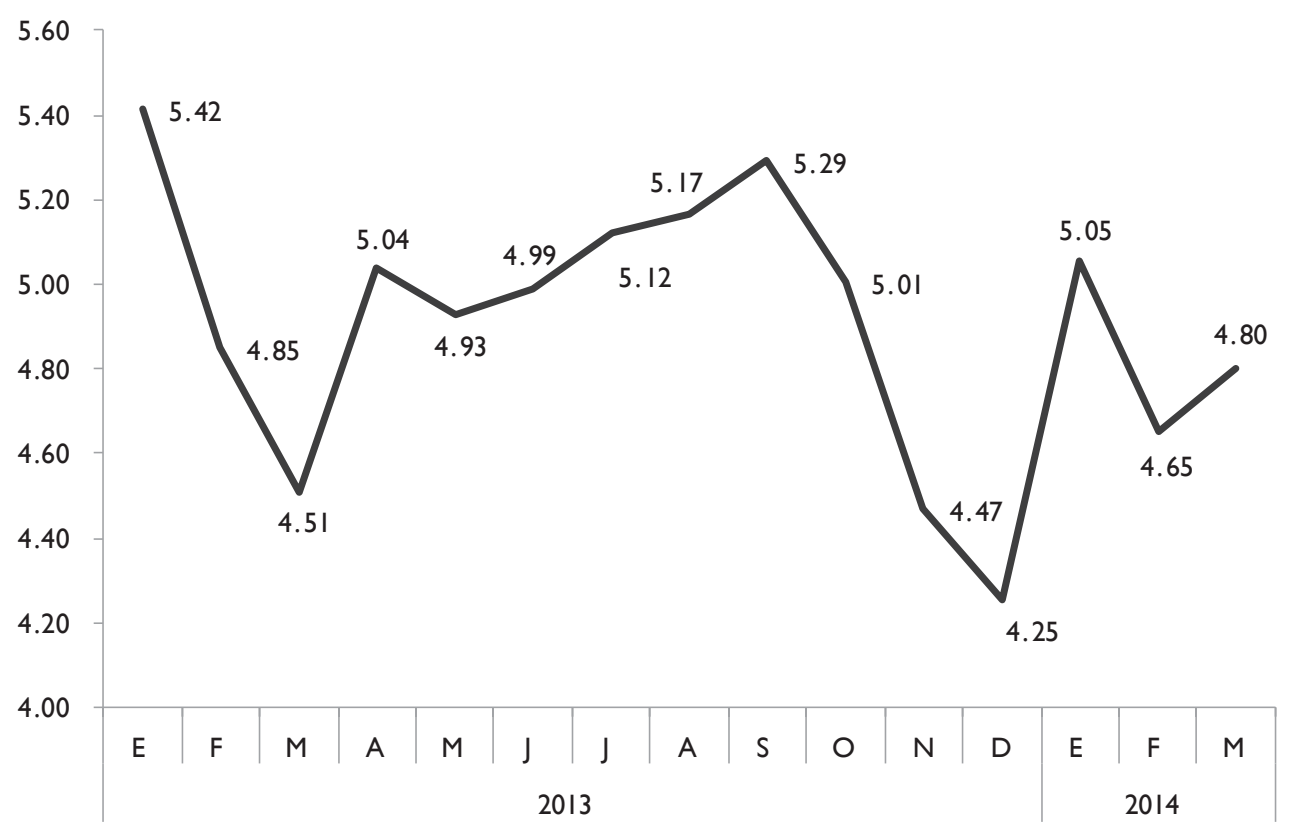

Fuente: elaboración propia con datos del INEGI.

\section{Tipo de Cambio}

En los primeros tres meses del año, la cotización del dólar frente al peso mexicano registró un mínimo de 12.86 pesos por dólar (ppd) y un máximo de 13.49 ppd. Así, en lo que va del año 2014, el tipo de cambio FIX registra un nivel promedio de 13.23 ppd y una apreciación del tipo de cambio de 5 centavos. 
Gráfica 6

Tipo de Cambio FIX, 2013-2014

(Pesos por dólar)

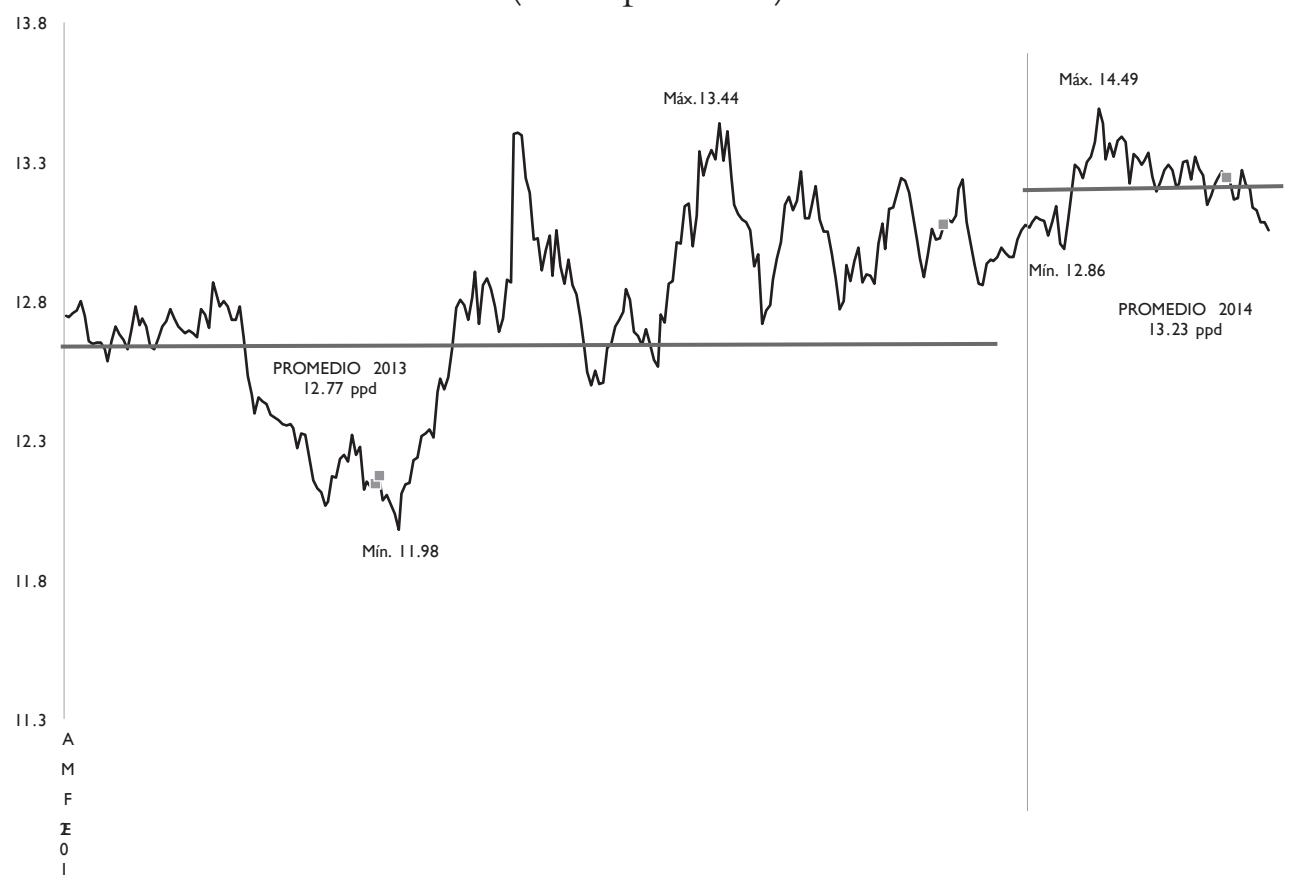

Fuente: elaboración propia con datos del Banco de México.

\section{Reservas Internacional}

Las reservas internacionales cerraron al primer trimestre de 2014 con un nuevo máximo histórico de 182742 millones de dólares. Asimismo, se registró un crecimiento acumulado de 6220 millones de dólares con respecto al cierre de 2013. 
Gráfica 7

Reservas Internacionales Netas, 2013-2014

(Miles de millones de dólares)

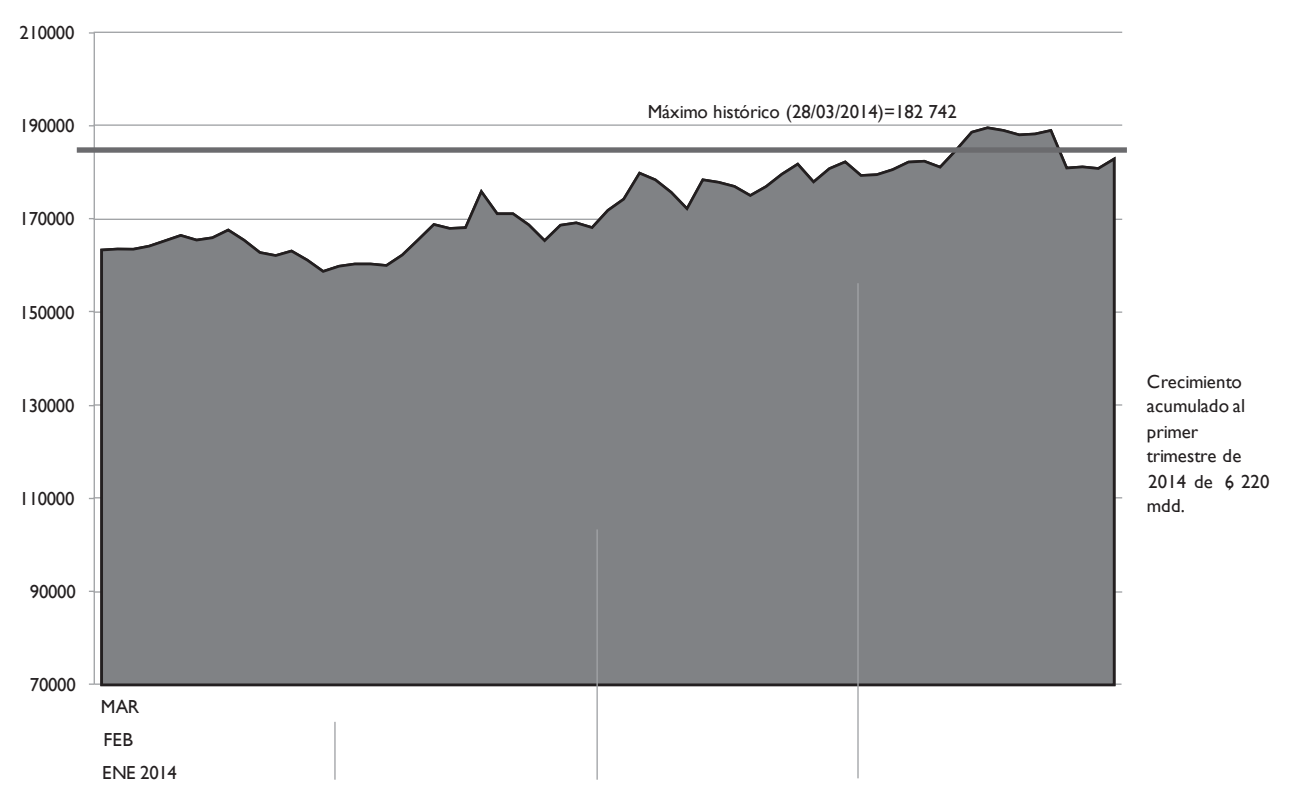

Fuente: elaboración propia con datos del Banco de México.

\section{Finanzas Públicas}

Al primer bimestre del año 2014, el balance público registró un déficit de 45.7 mil millones de pesos. Por su parte, el balance primario presento un déficit de 7.3 mil millones de pesos. Si se excluye la inversión de Pemex, el balance público presenta un superávit de 18 mil millones de pesos. Cabe mencionar que estos resultados son congruentes con las metas para estas variables aprobadas por el H. Congreso de la Unión para el presente año.

Por su parte, los ingresos presupuestarios del sector público ascendieron a febrero de 2014 a 650 mil millones de pesos, esto es, cifra superior en $3.1 \%$ en términos reales a la registrada en el mismo periodo del año anterior. Asimismo, en el primer bimestre del año, el gasto neto presupuestario del sector público ascendió a 692.1 mil millones de pesos, esto es, monto superior al registrado en 2013 en 19 por ciento real. 


\begin{tabular}{|c|c|c|}
\hline \multicolumn{3}{|l|}{$\begin{array}{l}\text { Cuadro } 1 \\
\text { Situación Financiera del Sector Público, 2013-2014 } \\
\text { (Millones de pesos) }\end{array}$} \\
\hline \multirow{2}{*}{ Concepto } & \multicolumn{2}{|c|}{ Enero - febrero } \\
\hline & 2013 & 2014 \\
\hline Balance Público & $53,842.8$ & $-45,727.6$ \\
\hline Balance Público sin inversión de Pemex & $90,705.3$ & $17,997.3$ \\
\hline Balance presupuestario & $47,060.4$ & $-42,123.8$ \\
\hline Ingreso presupuestario & $604,367.1$ & $650,001.8$ \\
\hline Petrolero & $184,763.3$ & $190,926.4$ \\
\hline Gobierno Federal & $132,242.6$ & $129,169.9$ \\
\hline Pemex & $52,520.7$ & $61,756.5$ \\
\hline No petrolero & $419,603.8$ & $459,075.4$ \\
\hline Gobierno Federal & $330,911.2$ & $362,977.0$ \\
\hline Tributarios & $300,562.4$ & $338,986.7$ \\
\hline No tributarios & $30,348.8$ & $23,990.3$ \\
\hline Organismos y empresas & $88,692.6$ & $96,098.4$ \\
\hline Gasto neto presupuestario & $557,306.8$ & $692,125.6$ \\
\hline Programable & $422,091.2$ & $525,189.9$ \\
\hline No programable & $135,215.5$ & $166,935.7$ \\
\hline Balance de entidades bajo control presupuestario indirecto & $6,782.4$ & $-3,603.8$ \\
\hline Balance primario & $76,163.6$ & $-7,281.4$ \\
\hline
\end{tabular}

Fuente: elaboración propia con datos de la SHCP.

Asimismo, los recursos transferidos a las entidades federativas y municipios a través de participaciones, aportaciones federales y otras transferencias aumentaron $11.2 \%$ real. Cabe mencionar en lo particular, que las participaciones federales crecieron en el primer bimestre en $15.4 \%$ en términos real.

Por último, cabe resaltar en este apartado, que el precio de la mezcla mexicana de petróleo de exportación se actualizó considerando los precios observados en los primeros meses del año, así como el precio implícito en los futuros del crudo. De igual forma, se consideraron las condiciones económicas prevalecientes a nivel internacional y la evolución reciente del mercado petrolero. Ello dio como resultado una estimación del precio promedio para 2014 de 89 dólares por barril, mayor que el precio de $85 \mathrm{dpb}$ aprobado por el H. Congreso de la Unión en el Paquete Económico para este año. 


\section{Pronósticos de la economía mexicana para el cierre de 2014}

Con los datos macroeconómicos arrojados en el primer trimestre del presente año, se estima que a finales del 2014 el PIB de México registrará un crecimiento de alrededor de 3.9 por ciento.

Asimismo, se estima que durante 2014 las exportaciones de México tendrán un incremento mayor que el registrado en el año anterior, de manera consistente con la evolución esperada para la producción industrial de los Estados Unidos. En particular, se prevé una expansión anual de $6.1 \%$ en el valor real en pesos de las exportaciones de bienes y servicios. La generación continua de empleos formales, el dinamismo del otorgamiento de crédito y del gasto público federal (especialmente en la creación de infraestructura), así como los primeros efectos de las reformas estructurales aprobadas en 2013 sustentarían el crecimiento de la inversión (6.3\%) y del consumo (3.5 por ciento).

Por otra parte, se espera que el crecimiento anticipado para la demanda externa del país, así como la apertura y ampliación reciente de plantas automotrices, se traduzca en una expansión significativa de la producción manufacturera y de los servicios relacionados con el comercio exterior. Por otro lado, se estima que la demanda interna impulsará a la industria de la construcción y los servicios menos relacionados con el sector externo.

\begin{tabular}{|c|c|c|}
\hline \multicolumn{3}{|c|}{$\begin{array}{l}\text { Cuadro } 2 \\
\text { Oferta y Demanda Agregada, 2013-2014/1 } \\
\text { (Variación real anual) }\end{array}$} \\
\hline & 2013 & 2014 \\
\hline Oferta & 1.1 & 4.6 \\
\hline PIB & 1.1 & 3.9 \\
\hline Importaciones & 1.2 & 6.7 \\
\hline Demanda & 1.1 & 4.6 \\
\hline Consumo & 2.3 & 3.5 \\
\hline Formación de capital ${ }^{/ 1}$ & -1.8 & 6.3 \\
\hline Exportaciones & 1.4 & 6.1 \\
\hline
\end{tabular}


Asimismo, se proyecta que al cierre del año la inflación sea de alrededor de $3.9 \%$, dentro del intervalo de variabilidad de 3\% más/menos un punto porcentual establecido como objetivo por el Banco de México.

El entorno macroeconómico previsto para 2014 presenta riesgos que podrían perturbar las trayectorias estimadas para las variables. Entre los riesgos a la baja destacan los siguientes:

- Menor dinamismo de la economía de Estados Unidos y la economía mundial que los anticipados.

- Elevada volatilidad en los mercados financieros internacionales y disminución de los flujos de capitales a los países emergentes. En particular, esto podría ocurrir por los efectos del proceso de normalización de la política monetaria en Estados Unidos.

- Tensión geopolítica en el Medio Oriente y Europa del Este, que puede ocasionar repuntes en las cotizaciones internacionales de materias primas y una mayor aversión al riesgo.

De acuerdo con la SHCP, la proyección de las finanzas públicas para 2014, considera la actualización del pronóstico para el precio promedio anual de la mezcla mexicana de exportación de petróleo, el cual pasa de 85 dólares por barril que se utilizaron en la elaboración de la LIF 2014 a 89 dólares por barril, así como de la estimación del tipo de cambio promedio anual del peso frente al dólar de Estados Unidos, que pasa de 12.9 a 13.1 pesos por dólar.

Asimismo, se actualizaron las estimaciones de los Adeudos Fiscales de Ejercicios Anteriores (ADEFAS) con el dato de los diferimientos de pagos efectivamente registrados al cierre de 2013.

Considerando lo anterior, se estima que los ingresos presupuestarios serán superiores en 29.9 miles de millones de pesos a los previstos en la LIF2014, lo que se explica por los mayores ingresos petroleros que resultan de un mayor precio del petróleo y tipo de cambio con respecto a lo programado. Los ingresos excedentes que en su caso se obtengan en 2014 serán aplicados conforme a las disposiciones establecidas en la LFPRH.

Para el gasto no programable, se prevé un monto superior en $12.4 \mathrm{mil} \mathrm{mi-}$ llones de pesos al aprobado para 2014, el cual resulta del mayor pago de Adefas. Por su parte, el techo del gasto programable se incrementa en 17.5 miles de millones de pesos al considerar las ampliaciones sustentadas en los ingresos excedentes previstos, incluyendo la aportación de 5.2 miles de millones de pesos 
para el Fondo de Estabilización de los Ingresos de las Entidades Federativas (FEIEF) provenientes del derecho extraordinario sobre extracción de petróleo.

Finalmente, se estima que los Requerimientos Financieros del Sector Público (RFSP) en 2014 serán equivalentes a $4.1 \%$ del PIB, permaneciendo en el nivel previsto para la aprobación del Paquete Económico para el 2014. Con ello, el Saldo Histórico de los Requerimientos Financieros del Sector Público (SHRFSP) pasaría de $40.4 \%$ del PIB anual en 2013 a $41.8 \%$ al cierre de 2014.

\begin{tabular}{|c|c|c|}
\hline \multicolumn{3}{|l|}{$\begin{array}{l}\text { Cuadro } 3 \\
\text { Escenario Macroeconómico } 2014-2015^{/ \mathrm{e}}\end{array}$} \\
\hline Concepto & 2014 & 2015 \\
\hline \multicolumn{3}{|l|}{ Producto Interno Bruto } \\
\hline Crecimiento \% real & 3.9 & 4.7 \\
\hline Nominal (miles de millones de pesos) & $17,358.6$ & $18,846.7$ \\
\hline \multicolumn{3}{|l|}{ Inflación } \\
\hline Dic. / dic. & 3.9 & 3.0 \\
\hline \multicolumn{3}{|l|}{ Tipo de cambio nominal } \\
\hline Promedio & 13.1 & 13.0 \\
\hline \multicolumn{3}{|l|}{ Tasa de interés (Cetes 28 días) } \\
\hline Nominal fin de periodo, $\%$ & 3.8 & 4.3 \\
\hline Nominal promedio, $\%$ & 3.4 & 4.0 \\
\hline Real acumulada, \% & -0.4 & 1.1 \\
\hline \multicolumn{3}{|l|}{ Cuenta Corriente } \\
\hline Millones de dólares & $-24,224.8$ & $-25,489.3$ \\
\hline$\%$ del PIB & -1.8 & -1.8 \\
\hline \multicolumn{3}{|l|}{ Balance fiscal, \% del PIB } \\
\hline Con inversión de Pemex & -3.5 & -3.0 \\
\hline Sin inversión de Pemex & -1.5 & -1.0 \\
\hline \multicolumn{3}{|l|}{ Petróleo (canasta mexicana) } \\
\hline Precio promedio (dls. / barril) & 89.0 & 75.0 \\
\hline Plataforma de producción promedio (mbd) & $2,520.0$ & $2,620.0$ \\
\hline Plataforma de exportación promedio (mbd) & $1,170.0$ & $1,240.0$ \\
\hline \multicolumn{3}{|l|}{ Gas } \\
\hline Precio promedio (dólares / MMBtu) & 4.7 & 4.3 \\
\hline
\end{tabular}




\section{Conclusiones}

Ha transcurrido el primer trimestre del año y la economía mexicana continúa sin crecimiento, estancada en un escenario de incertidumbre.

Las promesas y proyecciones de crecimiento que ofrecieron las reformas estructurales del 2013, no dan señales aún de materializarse, mucha gente opina que habrá que esperar a que se concreten las leyes secundarias, para entonces si ver los verdaderos resultados.

Cabe mencionar que uno de los principales compromisos de la Administración del Presidente de la República, Enrique Peña Nieto es el crecimiento económico incluyente. Por lo anterior, el año pasado se impulsaron una serie de reformas estructurales en diversos sectores de la economía, para de que cada una de ellas contribuya al logro de dicho objetivo.

Muchas de estas modificaciones también tienen como objetivo común acelerar el crecimiento de nuestra productividad, particularmente en aquellos sectores de la economía que no han sido expuestos a la competencia internacional a través del libre comercio.

Así vemos que la Reforma Laboral, la Reforma de Telecomunicaciones, de Competencia Económica, la Reforma Financiera y la Reforma Energética tienen en común "abrirse a la competencia".

Por último, el entorno macroeconómico previsto para México en 2014 presenta riesgos, esto es, dependiendo de los resultados económicos Norteamericanos y de la zona Euro, mismos que podrían perturbar las trayectorias estimadas impactando tanto a los mercados financieros nacionales como internacionales, así como el precio del petróleo y por supuesto que generaría una tensión geopolítica. 